In 1994, Dake and coworkers ${ }^{3}$ reported the feasibility of endovascular stent-grafting for aneurysms of the descending thoracic aorta. Mitchell and associates ${ }^{1}$ reported good late results with this technique. Our group has reported the effectiveness of endovascular stents in the treatment of acute aortic dissections in an animal model. ${ }^{4}$ The Stanford group clinically applies stent-grafting in the treatment of aortic dissections and currently in the treatment of acute dissections with obliteration of the true lumen. ${ }^{5}$ However, stent-graft repair of aortic dissections in the acute phase is not common.

This is the first report of successful endovascular stentgraft repair of an acute type A aortic dissection with an intimal tear in the descending aorta. Completion of the stent-graft repair for this subtype of type A dissection depends on the location of the intimal tear. The distance between the origin of the subclavian artery and the tear is an important determinant of the applicability of this treatment. In our experience, a distance of at least $1.5 \mathrm{~cm}$ is needed for the stent-graft placement to be safe. It appears that endovascular stent-grafting is a good therapeutic option in acute type A dissections with intimal tears in the descending aorta, particularly in light of the difficulty of the surgical approach.

\section{REFERENCES}

1. Mitchell RS, Dake MD, Semba CP, Fogarty TJ, Zarins CK, Liddell RP, et al. Endovascular stent-graft repair of thoracic aortic aneurysms. J Thorac Cardiovasc Surg 1996;111:1054-62.

2. Kazui T, Tamiya Y, Tanaka T, Komatsu S. Extended aortic replacement for acute type A dissection with the tear in the descending aorta. J Thorac Cardiovasc Surg 1996;112:973-8.

3. Dake MD, Miller DC, Semba CP, Mitchell RS, Walker PJ, Liddell RP. Transluminal placement of endovascular stentgrafts for the treatment of descending thoracic aortic aneurysms. N Engl J Med 1994;331:1729-34.

4. Kato N, Hirano T, Takeda K, Nakagawa T, Mizumoto T, Yuasa H, et al. Treatment of aortic dissections with a percutaneous intravascular endoprosthesis: comparison of covered and bare stents. J Vasc Interv Radiol 1994;5:805-12.

5. Slonim SM, Nyman U, Semba CP, Miller DC, Mitchell RS, Dake MD. Aortic dissection: percutaneous management of ischemic complications with endovascular stents and balloon fenestration. J Vasc Surg 1996;23:241-53.

\title{
ULTRAFAST COMPUTED TOMOGRAPHY FOR MINIMALLY INVASIVE CORONARY ARTERY BYPASS GRAFTING
}

\author{
Toshiya Ohtsuka, MD, ${ }^{\text {a }}$ Shinichi Takamoto, MD, ${ }^{a}$ Munemoto Endoh, MD, ${ }^{\text {a }}$ Minoru Ono, MD, ${ }^{a}$ and \\ Manabu Minami, MD, ${ }^{\text {b }}$ Tokyo, Japan
}

In minimally invasive coronary artery bypass grafting (MICABG), the coronary artery has to be identified and anastomosed via a small incision. ${ }^{1,2}$ Deep, nonpalpable coronary arteries should be excluded from this approach, and a small thoracotomy should be made just above an anastomosis to the left anterior descending artery (LAD). ${ }^{3}$ We have been using ultrafast computed tomography $(\mathrm{CT})$ for preoperative anatomic assessment of the LAD in patients undergoing MICABG. In the enhanced pictures obtained by ultrafast $\mathrm{CT}$, the coronary arteries can be imaged distinctly and assessed anatomically. In this study, the Imatron C-100 scanner (Imatron, Inc., San Francisco, Calif.) was used. Each picture of a $6 \mathrm{~mm}$ slice

From the Departments of Cardiothoracic Surgery ${ }^{\mathrm{a}}$ and Radiology, ${ }^{\text {b }}$ University of Tokyo, Tokyo, Japan

Received for publication Jan. 27, 1998; accepted for publication March 3, 1998.

Address for reprints: Toshiya Ohtsuka, MD, Department of Cardiothoracic Surgery, University of Tokyo, 7-3-1 Hongo, Bunkyo-ku, Tokyo 113, Japan.

J Thorac Cardiovasc Surg 1998;116:173-4

Copyright (c) 1998 by Mosby, Inc.

0022-5223/98 $\$ 5.00+0 \quad \mathbf{1 2 / 5 4 / 9 0 0 0 9}$ was completed in 0.05 second and taken from the origin of the internal thoracic artery (ITA) down to the apex of the heart. After institutional review board approval and written informed patient consent had been obtained, the study was performed in eight consecutive patients undergoing MICABG. Four of the patients had previously undergone conventional CABG via sternotomy; one of the four had also undergone left thoracotomy, and another of the four had also undergone left thoracotomy for pneumonectomy. One patient had had a previous sternotomy for thymectomy and one a left thoracotomy for lobectomy. In all cases, the left ITA and LAD were distinctly imaged in the pictures obtained by ultrafast CT scan. In each patient, the LAD was superficial. Positioning of a minithoracotomy was determined from the pictures by measuring the distances between the LAD and the median line or the left nipple. In each case, a small incision shorter than $5 \mathrm{~cm}$ was made, and the LAD was identified for anastomosis to the left ITA. In the five patients with previous sternotomies, the LADs were shifted medially and anteriorly near the left ITAs, which were harvested directly via small incisions (Fig. 1). In the other three, the left ITAs were harvested thoracoscopically through ports. ${ }^{4}$ In each case, postoperative angiography showed that the left ITA was correctly anastomosed to the LAD. With ultrafast CT scan, the 


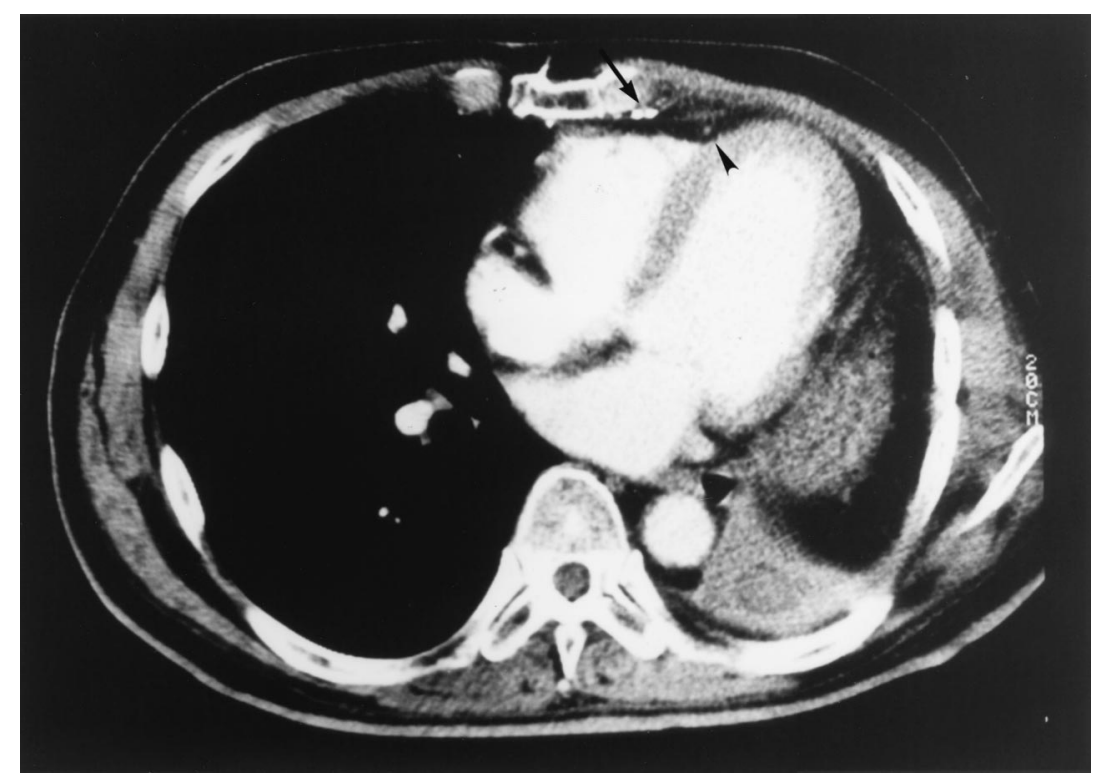

Fig. 1. Enhanced ultrafast $\mathrm{CT}$ scan of a patient with a previous sternotomy for CABG and left thoracotomy for pneumonectomy. The LAD (arrowhead) is superficial and shifted medially and anteriorly near the left ITA (arrow).

depth of the LAD can be assessed and intramuscular arteries can be excluded from the MICABG approach before the operation. Furthermore, a minimum-sized thoracotomy can be made just above the LAD, allowing minimal dissection of pleural or pericardial adhesions in patients who have had previous sternotomies or thoracotomies.

\section{REFERENCES}

1. Boonstra PW, Grandjean JG, Mariani MA. Improved method for direct coronary grafting without $\mathrm{CPB}$ via anterolateral small thoracotomy. Ann Thorac Surg 1997;63:567-9.
2. Acuff TE, Landreneau RJ, Griffith BP, Mack MJ. Minimally invasive coronary artery bypass grafting. Ann Thorac Surg 1996;61:135-7.

3. Landreneau RJ, Mack MJ, Magovern JA, et al. "Keyhole" coronary artery bypass surgery. Ann Surg 1996;224:453-62.

4. Ohtsuka T, Wolf RK, Hiratzka LH, Wurnig P, Flege JB Jr. Thoracoscopic internal mammary artery harvest for MICABG using the Harmonic Scalpel. Ann Thorac Surg 1997;63:S107-9.

\section{SYNDROME X: RELIEF BY TRANSMYOCARDIAL REVASCULARIZATION}

Allan M. Lansing, MD, PhD, Louisville, Ky.

From The Heart Institute, Audubon Regional Medical Center, Louisville, Ky.

Received for publication Feb. 10, 1998; accepted for publication March 3, 1998.

Address for reprints: Allan M. Lansing, MD, PhD, The Heart Institute, Audubon Regional Medical Center, One Audubon Plaza Dr., Louisville, KY 40217.

J Thorac Cardiovasc Surg 1998;116:174-6
Syndrome X, a term used by Kemp, ${ }^{1}$ and the more descriptive term "microvascular angina" are used to describe cases of typical angina, normal coronary arteries, and no other cardiac cause for angina such as mitral valve prolapse, ventricular hypertrophy, aortic valve disease,

Copyright $(0) 1998$ by Mosby, Inc.

$0022-5223 / 98 \$ 5.00+0 \quad \mathbf{1 2 / 5 4 / 9 0 0 1 0}$ 